\title{
Electroencephalography and Epilepsy Course at UH Cleveland Medical Center, Cleveland, Ohio, United States
}

\author{
Jun T. Park ${ }^{1,2,12}$ Michael Devereaux ${ }^{2,12}$ Hesham Abboud ${ }^{3,12}$ Fareeha Ashraf ${ }^{4,12}$ Mark Cohen ${ }^{5,12}$ \\ Marta Couce ${ }^{5,12}$ Suzanne DeBrosse ${ }^{6,12}$ Philip Fastenau ${ }^{3,12}$ Guadalupe Fernandez-Baca Vaca ${ }^{2,12}$ \\ Naiara Garcia-Losarcos ${ }^{2,12}$ Mustafa Kahriman ${ }^{4,12}$ Nuria Lacuey $^{2,12}$ Marge Marsey $^{7}$ \\ Jonathan Miller $^{8,12}$ Carol Rosen $^{9,12}$ Asim Shahid ${ }^{1,2,12}$ Rachel Tangen $^{10,12}$ Michael Wien ${ }^{11,12}$ \\ Hans Lüders 2,12
}

${ }^{1}$ Division of Pediatric Epilepsy, Department of Pediatrics, University Hospitals Rainbow Babies and Children's Hospital, Cleveland, Ohio, United States

2 Epilepsy Center, Neurological Institute, Department of Neurology, University Hospitals of Cleveland Medical Center, Cleveland, Ohio, United States

${ }^{3}$ Department of Neurology, Neurological Institute, University Hospitals of Cleveland Medical Center, Cleveland, Ohio, United States

${ }^{4}$ Department of Neurology, Louis Stokes Veterans Affairs Medical Center, Cleveland, Ohio, United States

${ }^{5}$ Department of Pathology, University Hospitals of Cleveland Medical Center, Cleveland, Ohio, United States

${ }^{6}$ Center for Human Genetics, Department of Genetics and Genome Sciences, University Hospitals Cleveland Medical Center, Cleveland, Ohio, United States

${ }^{7}$ Clinical Nutrition Services, Digestive Health Institute, University Hospitals Rainbow Babies and Children's Hospital, Cleveland, Ohio, United States
Address for correspondence Jun T. Park, MD, UH Case Medical Center, Cleveland, Ohio, United States (e-mail: jun.park@uhhospitals.org).

8 Division of Functional Neurosurgery, Department of Neurosurgery, Neurological Institute, University Hospitals of Cleveland Medical Center, Cleveland, Ohio, United States

${ }^{9}$ Division of Pediatric Pulmonology and Sleep Medicine, Department of Pediatrics, University Hospitals Rainbow Babies and Children's Hospital, Cleveland, Ohio, United States

${ }^{10}$ Division of Developmental and Behavioral Pediatrics and Psychology, Department of Pediatrics, University Hospitals Rainbow Babies and Children's Hospital, Cleveland, Ohio, United States

${ }^{11}$ Division of Pediatric Radiology, Department of Radiology, University Hospitals of Cleveland Medical Center, Cleveland, Ohio, United States

${ }^{12}$ Case Western Reserve University School of Medicine, Cleveland, Ohio, United States

J Pediatr Epilepsy 2019;8:2-10.

\section{Abstract}

\section{Keywords}

- UH EEG/epilepsy course

- UH Cleveland EEG/ epilepsy course

- electroencephalography and epilepsy course

- EEG unknown session

- EEG seizure session
Prof. Hans Lüders organized the first International Electroencephalography (EEG)/ Epilepsy course in Cleveland (Ohio, United States) in 1979. His vision was to impart a framework of basic knowledge in EEG and epilepsy. The course participants are assumed to have no prior knowledge of EEG or epilepsy. As such, the course is structured and paced to meet the expectations set forth by the organizing committee at the completion of the course. The curriculum has evolved over the years to reflect advancement of the field. There is an added emphasis on semiology (seizure semiology) and epileptic disorders. Also, the course content has expanded to include broader topics such as the intersection between epilepsy and sleep medicine for both adults and children. The course lasts 8 weeks and is offered twice a year, free of charge, in winter and summer at the University Hospital in Cleveland, Ohio, United States. The average class size ranges from 25 to 30 , composed of individuals from around the world. The class hours are generally from 8 a.m. to 3:30 p.m. Daily attendance is expected as new concepts quickly build on previous ones. Midterm and

(DJun T. Park's ORCID is https://orcid.org/0000-0002-9325-0038.

received

February 19, 2019

accepted

April 2, 2019

published online

June 7, 2019
Issue Theme Pediatric Epilepsy Pioneers and Educational Programs Worldwide; Guest Editors: Vincenzo Salpietro, MD, and Stephanie Efthymiou, MSc
Copyright (c) 2019 by Georg Thieme

Verlag KG, Stuttgart . New York
DOI https://doi.org/ $10.1055 / \mathrm{s}-0039-1692146$. ISSN 2146-457X. 
- seizure semiology session

- epilepsy surgical case session

- anamnesis session

- Hans Lüders

- seizure semiology final examinations are used for evaluations. Both written and verbal feedbacks on homework assignments are given daily. At the end of the course, a certificate of completion is awarded. The purpose of this article is to discuss the structural details of this intensive educational course that has been offered for 40 years.

\section{Introduction}

Prof. Hans Lüders organized the first International Electroencephalography (EEG)/Epilepsy course in Cleveland (Ohio, United States) in 1979. His vision was to impart a framework of basic knowledge in EEG and epilepsy. The course participants are assumed to have no prior knowledge of EEG or epilepsy. As such, the course is structured and paced to meet the expectations set forth by the organizing committee at the completion of the course. The curriculum has evolved over the years to reflect advancement of the field. There is an added emphasis on semiology (seizure semiology [SS]), and epileptic disorders. Also, the course content has expanded to include broader topics like the intersection between epilepsy and sleep medicine for both adults and children. The course lasts 8 weeks and is offered twice a year, free of charge, in winter and summer at the University Hospital (UH) in Cleveland, Ohio, United States. The average class size ranges from 25 to 30 , composed of individuals from around the world. The class hours are generally from 8 a.m. to 3:30 p.m. Daily attendance is expected as new concepts quickly build on previous ones. Midterm and final examinations are used for evaluations. Both written and verbal feedbacks on homework assignments are given daily. At the end of the course, a certificate of completion is awarded. The purpose of this article is to discuss the structural details of this intensive educational course that has been offered for 40 years.

\section{Course Faculty}

The core faculty consists of 6 adult and 2 pediatric epileptologists. Each faculty member is responsible for his/her corresponding didactic week. The current core faculty consists of Drs. Hans Lüders, Michael Devereaux, Jun Park, Asim Shahid, Guadalupe Fernandez Baca-Vaca, Fareeha Ashraf, Nuria Lacuey, and Naiara Garcia. All faculty members have previously taken the course, have been fellowship-trained by Hans Lüders and colleagues, and are board-certified. In addition, various experts from corresponding departments are invited to give lectures on topics, such as neuropsychology, neuroimmunology, neurosurgery, sleep, neurogenetics, neuropathology, and neuroradiology.

\section{Supportive Staff and System Set Up}

The bi-yearly course is supported by a full-time engineer of information technology and an administrative coordinator. The engineer ensures smooth operation of softwares that contain the course materials and flawless access to the course materials within the UH system. Access to any patient data is blocked.

The course coordinator is responsible for all administrative activities of the course from the initial communication with potential course participants, visas, identification badges, and addressing all administrative issues that may arise while the course is in progress.

All course handouts and learning materials are stored in an electronic "master" folder in the UH hospital system. The students are given a time-restricted access to files that do not contain any patient information. Within the "master" folder, there are subfolders that students can access for daily homework assignments including the electronic tracings of deidentified EEGs, the EEG report generating system, previous course lectures, and student materials.

\section{Course Participants}

The course is mandatory for the following trainees at $\mathrm{UH}$ Cleveland Medical Center (UHCMC): neurology residentsboth adult and pediatric, epilepsy and clinical neurophysiology fellows, EEG technologists, neurocritical care fellows, and epilepsy research scholars. In each course, there are 6 neurology residents, 2 to 3 epilepsy/neurophysiology fellows, and 2 neurocritical care fellows from UHCMC. The remainder of the course participants varies from year-toyear in their background and country of origin. There have been representatives from the United States and internationally by epileptologists, neurologists, functional neurosurgeons, registered epilepsy nurses, undergraduate/ graduate student researchers, and EEG technologists. Many countries have been represented, including Korea, China, Japan, Vietnam, Thailand, South Africa, Germany, Italy, Poland, Turkey, Spain, Australia, Iran, Egypt, Iraq, India, Pakistan, Colombia, Brazil, Chile, Portugal, Oman, Malaysia, Slovenia, Ecuador, United Kingdom, Ireland, and Russia. 


\section{Didactics}

\section{Part 1: Daily Homework}

There are two daily homework assignments-a 15-secondlong "EEG unknown" (40 total) and a routine EEG recording (40 total). Students analyze both and prepare a written report for each that are turned in at the beginning of the discussion. The teaching faculty member for the week after the discussion returns the corrected reports to the students. A sample of the EEG reporting system is provided in - Fig. $\mathbf{1}^{1}$ In addition, there are 2-hour long sessions weekly with senior faculty in attendance, one concentrating on a single 15-second epoch of an unknown EEG without montage (see below).

\section{Part 2: Weekly Recommended Reading Assignments}

There are three to five recommended reading assignments each week. The articles have been selected to accompany the concepts taught each week to enhance depth of understanding.

\section{Part 3: Weekly Fellow Conferences}

In addition to these daily homework exercises, there are two weekly morning conferences on two separate days that are jointly attended by epilepsy faculty, research scholars, and the current epilepsy and clinical neurophysiology fellows. A fellow from the UH Epilepsy Center presents a case corresponding to one of the five exercises shown below. Each session is moderated by a faculty member for an hour. During each session, the faculty member illustrates or emphasizes certain concepts that may arise. Each session is concluded with the fellow's presentation reviewing the epilepsy classification that includes etiology and comorbidities based on all available data. In addition, the fellow provides a 20-minute long review of a topic related to the case just presented. The presenter also prepares a 1- to 2-page handout on the review topic.

(1) "EEG unknown" session.

(2) "EEG seizure" session.

(3) "Seizure semiology" session.

(4) "Epilepsy surgical case" session.

(5) "Anamnesis" session.

\section{1. "EEG unknown" session}

A 15-second page of an EEG is displayed (with an EEG finding of interest selected by the presenter) without the montage. The actual montage is 1 of 6 established montages ( $\mathbf{- F i g . ~} \mathbf{2}$ ) at the UHCMC. Based on the features of EEG waveforms and any changes in the heart rate (by ECG), students determine the montage, the likely age of the patient, the level of consciousness of the patient, and the EEG finding(s)-both normal and abnormal. The answers need to be justified using neurophysiological features of the EEG. One volunteer from the audience verbally works through the exercise to reach the answers while a faculty member moderates. The same exercise is a part of daily homework assignment, but the answers are submitted on a provided

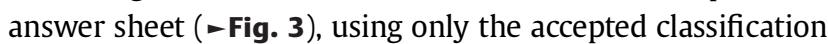
terms (-Fig. 4). ${ }^{2}$ The primary learning objective is to understand the fundamental neurophysiological features of EEG.

\section{2. "EEG seizure" session}

An EEG recording of a clinical seizure is shown first without the video. A volunteer from the audience analyzes the EEG seizure, page-by-page. The location of the epileptogenic zone (EZ) and SS, which are parts of the epilepsy classification, are

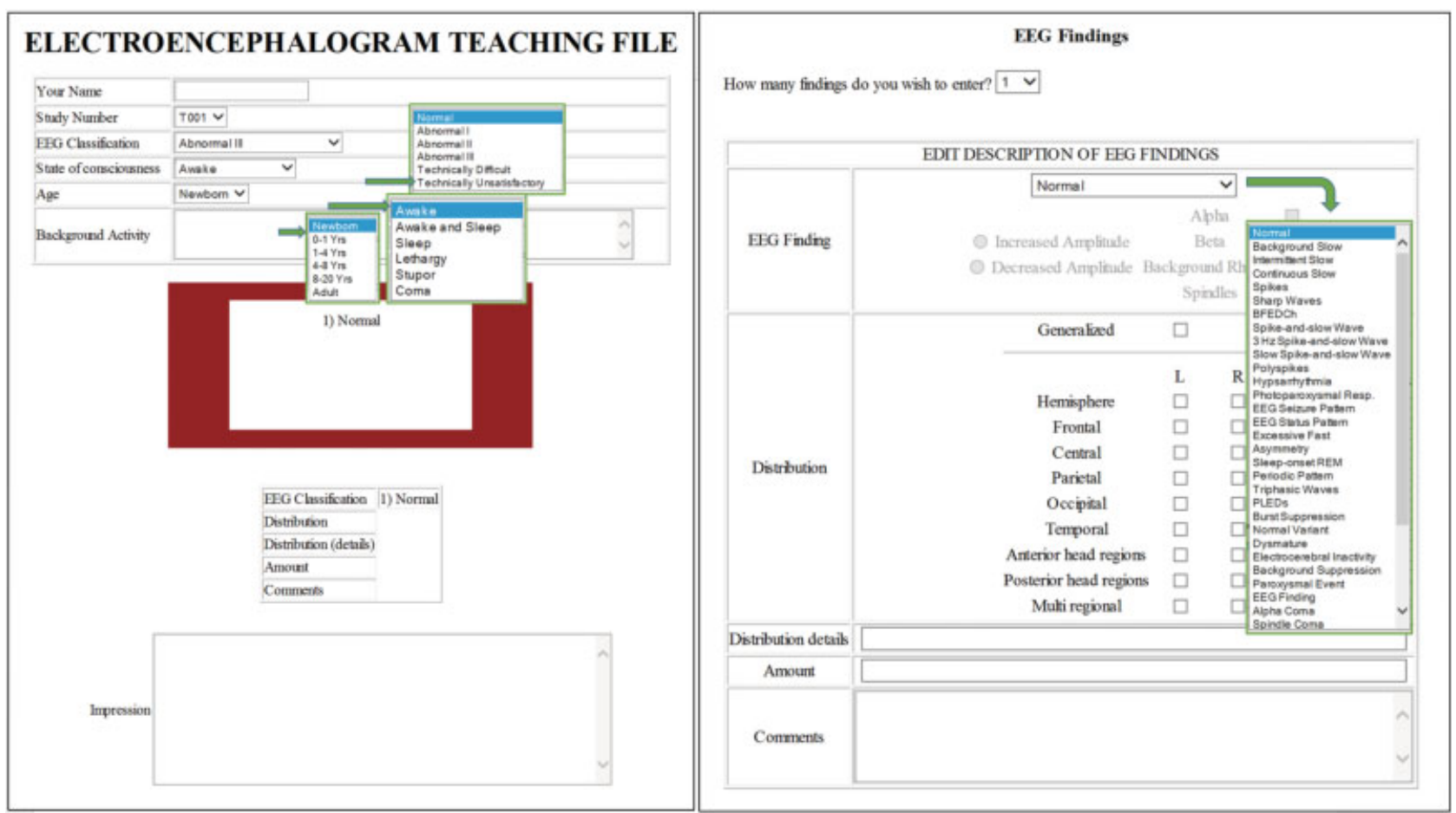

Fig. 1 Electroencephalography (EEG) reporting system (dropdown boxes contain the accepted terms). ${ }^{1}$ 


\begin{tabular}{|c|c|c|c|c|c|c|}
\hline Channel & Run 1 & Run 2 & Run 3 & Run 4 & Run 5 & Run 6 \\
\hline 1 & $F p 1-F 7$ & Fp1 - A1 & $F p 1-F 7$ & $\mathrm{Fp} 1-\mathrm{Cz}$ & F7 - F3 & $F p 1-F 7$ \\
\hline 2 & $\mathrm{~F} 7-\mathrm{T} 7$ & $\mathrm{~F} 7-\mathrm{A} 1$ & $\mathrm{Fp} 2-\mathrm{F} 8$ & $\mathrm{Fp} 2-\mathrm{Cz}$ & $\mathrm{F} 3-\mathrm{Fz}$ & F7 - FT9 \\
\hline 3 & $\mathrm{~T} 7-\mathrm{P} 7$ & $\mathrm{~T} 7-\mathrm{A} 1$ & $\mathrm{~F} 7-\mathrm{T} 7$ & $\mathrm{~F} 7-\mathrm{Cz}$ & $\mathrm{Fz}-\mathrm{F} 4$ & FT9 - T7 \\
\hline 4 & P7 - O1 & $\mathrm{P} 7-\mathrm{A} 1$ & F8 - T8 & $\mathrm{F} 8-\mathrm{Cz}$ & $F 4-F 8$ & $\mathrm{~T} 7-\mathrm{P} 7$ \\
\hline 5 & $\mathrm{Fp} 2-\mathrm{F} 8$ & $\mathrm{Fp} 2-\mathrm{A} 2$ & $\mathrm{~T} 7-\mathrm{P} 7$ & $\mathrm{~T} 7-\mathrm{Cz}$ & $\mathrm{A} 1-\mathrm{T} 7$ & $\mathrm{P} 7$ - O1 \\
\hline 6 & F8 - T8 & $\mathrm{F} 8-\mathrm{A} 2$ & T8 - P8 & $\mathrm{T} 8-\mathrm{Cz}$ & $\mathrm{T} 7-\mathrm{C} 3$ & $\mathrm{Fp} 2-\mathrm{F} 8$ \\
\hline 7 & T8 - P8 & $\mathrm{T} 8-\mathrm{A} 2$ & P7-01 & $\mathrm{P} 7-\mathrm{Cz}$ & $\mathrm{C} 3-\mathrm{Cz}$ & F8 - FT10. \\
\hline 8 & P8 - O2 & $\mathrm{P} 8$ - A2 & $\mathrm{P} 8-\mathrm{O} 2$ & $\mathrm{P} 8-\mathrm{Cz}$ & $\mathrm{Cz}-\mathrm{C}_{4}$ & FT10 - T8 \\
\hline 9 & $F p 1-F 3$ & $\mathrm{~F} 3-\mathrm{A} 1$ & $F P 1-F 3$ & $\mathrm{~F} 3-\mathrm{Cz}$ & $\mathrm{C} 4-\mathrm{T} 8$ & T8 - P8 \\
\hline 10 & $\mathrm{~F} 3-\mathrm{C} 3$ & $\mathrm{C} 3-\mathrm{A} 1$ & $\mathrm{FP} 2-\mathrm{F} 4$ & $\mathrm{~F} 4-\mathrm{Cz}$ & $\mathrm{T} 8-\mathrm{A} 2$ & $\mathrm{P} 8-\mathrm{O} 2$ \\
\hline 11 & $\mathrm{C} 3-\mathrm{P} 3$ & $\mathrm{P} 3-\mathrm{A} 1$ & $\mathrm{~F} 3-\mathrm{C}_{3}$ & $\mathrm{C} 3-\mathrm{Cz}$ & $\mathrm{P} 7-\mathrm{P} 3$ & FT9 - FT10 \\
\hline 12 & $\mathrm{P} 3$ - O1 & $\mathrm{O} 1-\mathrm{A} 1$ & $\mathrm{~F} 4-\mathrm{C} 4$ & $\mathrm{C} 4-\mathrm{Cz}$ & $\mathrm{P} 3-\mathrm{Pz}$ & $\mathrm{A} 1-\mathrm{A} 2$ \\
\hline 13 & $\mathrm{Fp} 2-\mathrm{F} 4$ & $\mathrm{~F} 4-\mathrm{A} 2$ & $\mathrm{C} 3-\mathrm{P} 3$ & $\mathrm{P} 3-\mathrm{Cz}$ & $\mathrm{Pz}-\mathrm{P} 4$ & $F p 1-F 3$ \\
\hline 14 & $\mathrm{~F} 4-\mathrm{C}_{4}$ & $\mathrm{C} 4-\mathrm{A} 2$ & $\mathrm{C} 4$ - P4 & $\mathrm{P} 4-\mathrm{Cz}$ & P4 - P8 & $\mathrm{F} 3-\mathrm{C}_{3}$ \\
\hline 15 & $\mathrm{C}_{4}-\mathrm{P}_{4}$ & $\mathrm{P} 4-\mathrm{A} 2$ & $\mathrm{P} 3-\mathrm{O} 1$ & $\mathrm{O} 1-\mathrm{Cz}$ & Fp1 - A1 & $\mathrm{C} 3-\mathrm{P} 3$ \\
\hline 16 & $\mathrm{P} 4-\mathrm{O} 2$ & $\mathrm{O} 2-\mathrm{A}_{2}$ & $\mathrm{P} 4-\mathrm{O} 2$ & $\mathrm{O} 2-\mathrm{Cz}$ & $\mathrm{Fp} 2-\mathrm{A} 2$ & $\mathrm{Fp} 2-\mathrm{F} 4$ \\
\hline 17 & $\mathrm{Fz}-\mathrm{Cz}$ & $\mathrm{Fz}-\mathrm{A} 2$ & $\mathrm{Fz}-\mathrm{Cz}$ & $\mathrm{FT} 9-\mathrm{Cz}$ & $\mathrm{O} 1-\mathrm{A} 1$ & $\mathrm{~F} 4-\mathrm{C}_{4}$ \\
\hline 18 & $\mathrm{Cz}-\mathrm{Pz}$ & $\mathrm{Cz}-\mathrm{A} 2$ & $\mathrm{Cz}-\mathrm{Pz}$ & $\mathrm{FT} 10-\mathrm{Cz}$ & $\mathrm{O} 2-\mathrm{A} 2$ & $\mathrm{C} 4-\mathrm{P} 4$ \\
\hline 19 & EKG & $\mathrm{Pz}-\mathrm{A} 2$ & EKG & $\mathrm{A} 1-\mathrm{Cz}$ & EKG & EKG \\
\hline 20 & & EKG & & $\mathrm{A} 2-\mathrm{Cz}$ & & \\
\hline 21 & & & & EKG & & \\
\hline
\end{tabular}

Fig. 2 Five montages.

proposed before a video of the seizure is analyzed. After the video is shown, the proposed localization of the EZ and SS are confirmed or modified. The primary learning objective is to learn how to analyze an EEG seizure and obtain all information about the SS without the video.

\section{3. "Seizure semiology" session}

A video of a paroxysmal event is shown. Students classify the paroxysmal event as either epileptic or nonepileptic. If epileptic, the seizure is classified using the four-dimensional epilepsy classification (Example 1). ${ }^{3,4}$ SS is proposed using only the approved terminology for seizure components (-Fig. 5) (Example 1). 2,5-9

After an epilepsy classification is proposed, the EEG seizure is shown for analysis by a volunteer from the audience. Finally, data from analysis of the video and EEG are combined to either confirm or modify the proposed epilepsy classification.

There are three learning objectives: (1) Learn how to differentiate epileptic from nonepileptic events based on semiology; (2) learn SS and the terms used to classify it; and (3) appreciate the epilepsy classification and its role in seizure management.

Example 1:

Patients with epileptic paroxysmal events

\section{Specify the following four "dimensions."}

A. Epileptogenic zone.

B. Seizure semiology.
C. Etiology.

D. Comorbidities.

Classification of seizure semiology:

Example:

1) Abdominal aura $\rightarrow$ (2) automotor (D) $\rightarrow$ (3) left clonic $\rightarrow$ (4) generalized clonic seizure

Lateralizing signs: left dystonia

Frequency: 1) 1/day 2) 4/month 4) Last seizure: 2012.

Specific instructions:

- Seizure classification should include a maximum of four components, each component specified by " $(\mathrm{x})$ " to indicate order of sequence.

- Use only approved terminology for seizure components.

- The term "seizure" is added to the last seizure type.

- Always specify at which component the patient loses consciousness or becomes dialeptic with a (D).

- If patient has epileptic and nonepileptic events $\rightarrow$ classify the 2 types of events independently

\section{Classification of lateralizing signs}

Lateralizing signs and diagnostic signs are not seizure components. They are added at the end of the classification as "additional signs." 


\begin{tabular}{|c|c|c|c|c|c|c|}
\hline \multicolumn{5}{|l|}{ Name } & \multicolumn{2}{|c|}{ Date } \\
\hline \multirow[t]{9}{*}{ Record \# } & Age & Montage & $\begin{array}{c}\text { Level of } \\
\text { Consciousness }\end{array}$ & Artifacts / Normal Variants & EEG Classification & Clinical Interpretatoin \\
\hline & Birth & $\overline{M 1}$ & awake & & & \\
\hline & 0 to 1 & $\mathrm{M} 2$ & drowsy & & & \\
\hline & 1 to 3 & $\mathrm{M} 3$ & sleep (II-IV) & & & \\
\hline & 3 to 7 & M4 & REM sleep & & & \\
\hline & 7 to 12 & M5 & lethargy & & & \\
\hline & 13 to 18 & M6 & stupor & & & \\
\hline & 18 to 60 & & coma & & & \\
\hline & over 60 & & & & & \\
\hline & Birth & $\overline{M 1}$ & awake & & & \\
\hline & 0 to 1 & $\mathrm{M} 2$ & drowsy & & & \\
\hline & 1 to 3 & $\mathrm{M3}$ & sleep (II-IV) & & & \\
\hline & 3 to 7 & $\mathrm{M} 4$ & REM sleep & & & \\
\hline & 7 to 12 & M5 & lethargy & & & \\
\hline & 13 to 18 & M6 & stupor & & & \\
\hline & 18 to 60 & & coma & & & \\
\hline & over 60 & & & & & \\
\hline & Birth & $\mathrm{M} 1$ & awake & & & \\
\hline & 0 to 1 & $\mathrm{M} 2$ & drowsy & & & \\
\hline & 1 to 3 & $M 3$ & sleep (III-IV) & & & \\
\hline & 3 to 7 & $\mathrm{M} 4$ & REM sleep & & & \\
\hline & 7 to 12 & M5 & lethargy & & & \\
\hline & 13 to 18 & M6 & stupor & & & \\
\hline & 18 to 60 & & coma & & & \\
\hline & over 60 & & & & & \\
\hline & Birth & $\overline{M 1}$ & awake & & & \\
\hline & 0 to 1 & M2 & drowsy & & & \\
\hline & 1 to 3 & M3 & sleep (IIIIV) & & & \\
\hline & 3 to 7 & M4 & REM sleep & & & \\
\hline & 7 to 12 & M5 & lethargy & & & \\
\hline & 13 to 18 & M6 & stupor & & & \\
\hline & 18 to 60 & & coma & & & \\
\hline & over 60 & & & & & \\
\hline & Birth & $\mathrm{M} 1$ & awake & & & \\
\hline & 0 to 1 & $\mathrm{M} 2$ & drowsy & & & \\
\hline & 1 to 3 & $\mathrm{M} 3$ & sleep (II-IV) & & & \\
\hline & 3 to 7 & $\mathrm{M} 4$ & REM sleep & & & \\
\hline & 7 to 12 & M5 & lethargy & & & \\
\hline & 13 to 18 & M6 & stupor & & & \\
\hline & 18 to 60 & & coma & & & \\
\hline & over 60 & & & & & \\
\hline
\end{tabular}

Fig. 3 Electroencephalography (EEG) unknown answer sheet.

Example: Psychic aura $\rightarrow$ left hand clonic $\rightarrow$ generalized tonic-clonic seizure

Additional signs: Right paradoxical clonic seizure Left postictal hemiplegia

Ictal tongue biting

\section{Classification of etiology}

Indicate as precisely as possible the condition that caused the epilepsy.

Example: Left parietal stroke (8.24.2017); right frontal meningioma, etc.

Always indicate date if an "accident" (trauma, stroke, etc.).

\section{Classification of comorbidities}

List all the medical conditions that are important for the management of the patient but are not included as etiologies.
Example: Right frontal craniotomy (2011), severe hyponatremia, severe mental retardation, autism, severe depression, etc.

Always list first the medical condition most important for the management of the patient.

\section{4. "Epilepsy surgical case" session}

A clinical fellow presents a presurgical case that had been previously presented without altering the original content. Students critique the organization and content of the PowerPoints for effective and succinct conveyance of the necessary information for recommendations of treatment. This part of the exercise takes up at least $50 \%$ of the session. A volunteer discusses his/her recommendation in the following format: (1) State the most likely location of the EZ. (2) Identify the supportive evidence for the localization of the EZ. (3) Propose a treatment option. If an invasive investigation is proposed, suggest a plan to either confirm or refute the hypothesis. If no invasive investigation is needed, state the reason and propose a follow-up plan. 


\begin{tabular}{|c|c|c|}
\hline EEG Classification & EEG Finding & EEG Finding \\
\hline Normal & Normal & Normal Variant \\
\hline Abnormal I & Background Slow & Dysmature \\
\hline Abnormal II & Intermittent Slow* & Electrocerebral Inactivity* \\
\hline Abnormal III & Continuous Slow* & Background Suppression* \\
\hline Technically difficult & Spikes* & Paroxysmal Event \\
\hline \multirow[t]{2}{*}{ Technically unsatisfactory } & Sharp Waves* & EEG Finding \\
\hline & BFEDCh $^{*}$ & Alpha Coma \\
\hline State of Consciousness & Spike-and-slow wave* & Spindle Coma \\
\hline Awake & $3 \mathrm{~Hz}$ Spike-and-slow wave* & Beta Coma \\
\hline Awake and Sleep & Slow Spike-and-slow wave* & Theta Coma \\
\hline Sleep & Polyspikes* & Delta Coma \\
\hline Lethargy & Hypsarrhythmia* & Alpha Stupor \\
\hline Stupor & Photoparoxysmal Resp." & Spindle Stupor \\
\hline \multirow[t]{2}{*}{ Coma } & EEG Seizure Pattern* & Beta Stupor \\
\hline & EEG Status Pattern" & Theta Stupor \\
\hline$\widehat{\text { Age }}$ & Excessive Fast & Delta Stupor \\
\hline Newborn & Asymmetry & \\
\hline $0-1$ year & Sleep-onset REM & \\
\hline $1-4$ years & Periodic Pattern * & \\
\hline 4-8 years & Triphasic Waves* & \\
\hline $8-20$ years & PLEDs* ${ }^{*}$ & \\
\hline \multirow[t]{2}{*}{\begin{tabular}{|l|l|l|l|l} 
Adult \\
\end{tabular}} & Burst Suppression* & \\
\hline & calization must b & d for these EEG Findings \\
\hline
\end{tabular}

Fig. 4 Electroencephalography (EEG) classification terms. ${ }^{2}$

Once a recommendation is reached, moderated by a faculty member, the presenting fellow reviews the actual consensus that was reached during the previous epilepsy surgery management conference and ends with an updated clinical outcome of the patient.

There are four learning objectives with this exercise: (1) learn how to present and construct a presurgical presentation effectively and succinctly; (2) formulate a hypothesis of the EZ based on supporting evidence; (3) plan an invasive evaluation, if needed, using intracerebral or subdural electrodes to confirm or refute one's hypothesis. If an invasive evaluation is not needed, discuss the next step in management; and (4) learn from the past experience.

\section{5. "Anamnesis" session}

A patient's initial history of a paroxysmal event is presented without alteration of the original text. Thereafter, students critique the content of the history. Based on the available information, the paroxysmal event is classified as either epileptic or nonepileptic and a four-dimensional epilepsy classification is constructed as in the "SS" session. After an epilepsy classification is proposed, a corresponding seizure video of the patient is shown. The learning objectives are: (1) improve history taking skills in patients with a chief complaint of a possible seizure; (2) formulate a hypothesis of the EZ; and (3) learn the semiological classification.

\section{Part 4: Weekly Didactic Sessions}

The didactic sessions that occur once a week are the Antiepileptic (AED) Drug Case Study, Epilepsy Surgery Case Conference, and Interactive EEG Reading Session. The latter occurs four times a week. Additional details of each session are outlined below. In addition, the course participants are required to attend epilepsy grand rounds that occur once a week outside of summer months. An example of a weekly schedule is provided in -Fig. 6 .

\section{Antiepileptic Drug Case Study}

This is an hour-long session that takes place once a week. The teaching faculty member of the week presents a patient's history from his/her practice. This is a session dedicated to discuss questions that may arise about AED selection, weaning, and switching of $\operatorname{AED}(s)$, side effects, dose adjustment, pharmacokinetics, etc.

\section{Epilepsy Surgery Case Conference}

During this weekly conference, students are exposed to both pediatric and adult epilepsy surgical cases as they are presented and discussed. In addition, data from any ongoing invasive monitoring are presented to discuss progress and planed conclusion of the monitoring.

\section{3. "EEG reading" session}

Scheduled 4 days a week, this is an interactive teaching session where a teaching staff reviews 2 samples of raw, 
8 Electroencephalography and Epilepsy Course at UH Cleveland Medical Center Park et al.

\begin{tabular}{|c|c|c|}
\hline & AUTONOMIC SEIZURE* & Kissing Seizure \\
\hline & Abdominal Seizure & Singing Seizure \\
\hline AURA $^{*}$ & Anisocoric Seizure* & Spitting Seizure \\
\hline Auditory Aura * & Anneir Seizure & Verbalization Seizure \\
\hline Autonomic Aura & Apneic seizure & SPECIAL SEIZURES* ${ }^{*}$ \\
\hline Abdominal Aura & Bradycardic Seizure & Astatic Seizures \\
\hline Choking Aura & Emetic Seizure & Atonic Seizures* \\
\hline Diaphoretic Aura & Fecal Incontinent Seizure & Fear Facies Seizure \\
\hline Dipsosic Aura & Hippus Seizure & Hypnopompic Seizure \\
\hline Pilomotor Aura ${ }^{*}$ & Hyperhydrotic Seizure ${ }^{*}$ & Hypomotor Seizure \\
\hline Sialorrheic Aura & Hypertensive Seizure & Negative Myoclonic Seizure" \\
\hline Tachycardic Aura & Hyperventilation Seizure & $\begin{array}{l}\text { Water Drinking Seizure } \\
\text { LATERALIING SIGNS* }\end{array}$ \\
\hline Urinary Aura & Lacrimatory Seizure & $\begin{array}{l}\text { LATERALIZING SIGNS* } \\
\text { Automotor Seizure with no Dialepsis }\end{array}$ \\
\hline $\begin{array}{l}\text { Urinary Aura } \\
\text { Vasomotor Aura * }\end{array}$ & Pilomotor Seizure* & $\begin{array}{l}\text { Automotor Seizure with no Dialepsis } \\
\text { Early Head Deviation* }\end{array}$ \\
\hline $\begin{array}{l}\text { Vasomotor Aura * } \\
\text { Gustatory Aura }\end{array}$ & Sexual Seizure & Figure of $4^{*}$ \\
\hline Gustatory Aura & Sialorrheic Seizure & Ictal Dystonia* \\
\hline Olfactory Aura & Tachycardic Seizure & Ictal Speech \\
\hline Psychic Aura & Urinary Seizure & Ictal Unilateral Automatisms ${ }^{*}$ \\
\hline Affective Aura & Vasomotor Seizure* & Ictal Unilateral Blinking* \\
\hline Pleasure Aura & DISCOGNITIVE SEIZURE & Immediate Postictal Speech \\
\hline Ecstasy Aura & Amnestic Seizure & M2e Sign* \\
\hline Religious Aura & Aphasic Seizure & Paradoxical Clonic Seizure* \\
\hline Sexual Aura & Apraxic Seizure & Paradoxical Versive Seizure ${ }^{*}$ \\
\hline Unpleasant Aura & Dialeptic Seizure & Postictal Aphasia \\
\hline Unpleasant Aura & MOTOR SEIZURE* & Postictal Hemianopsia ${ }^{*}$ \\
\hline Anger Aura & SIMPLE MOTOR SEIZURE* & Postictal Hemineglect ${ }^{*}$ \\
\hline Depression Aura & Clonic Seizure ${ }^{*}$ & Postictal Hemiparesis* \\
\hline Embarrassment Aura & Epileptic Spasm* & Postictal Nose Wiping ${ }^{*}$ \\
\hline Fear Aura & Myoclonic Seizure ${ }^{*}$ & Unilateral Pupillary Dilatation* \\
\hline Guilt Aura & Nystagmoid Seizure ${ }^{*}$ & DIAGNOSTIC SIGNS \\
\hline Cognitive Aura & Tonic Seizure ${ }^{*}$ & Body Turning Along Horizontal Body Axis \\
\hline Experiential Aura & Tonic-clonic Seizure ${ }^{*}$ & $\begin{array}{l}\text { Ictal Blinking } \\
\text { Ictal Pouting }\end{array}$ \\
\hline Familiarity Aura & Versive Seizure $^{*}$ & Ictal Tongue Biting \\
\hline Deja-vu Aura & Vocalization Seizure & Forceful Ictal Eye Closure \\
\hline Jamais-vu Aura & COMPLEX MOTOR SEIZURE & Forceful Ictal Mouth Closure \\
\hline Illusionary Aura & Alien limb Seizure & Postictal Apraxia \\
\hline Somatosensory Aura ${ }^{*}$ & Automotor Seizure & Postictal Blindness \\
\hline Vestibular Aura & Dacrystic Seizure & Postictal Bulimia \\
\hline $\begin{array}{l}\text { Vestibular Aura } \\
\text { Visual Aura* }\end{array}$ & Gelastic Seizure & Postictal Headache \\
\hline \multirow{2}{*}{ Ictal blindness ${ }^{*}$} & Hypermotor Seizure & $\begin{array}{l}\text { Postictal Psychosis } \\
\text { Postictal Stertorous Breathing }\end{array}$ \\
\hline & $\begin{array}{l}\text { Emotional hypermotor } \\
\text { Seizure }\end{array}$ & Postictal Urinary Incontinence \\
\hline
\end{tabular}

Fig. 5 Seizure semiology classification: teaching table. ${ }^{2,5,6,8,9}$

20-minute EEG data and moderates an interactive discussion. This is an opportunity for students to review EEG tracings and verbally generate a report.

\section{Evaluations}

There is no evaluation before the course as all participants are "assumed" to have no prior knowledge base of EEG or epilepsy. There are two formal written evaluations: midterm and final exams. An example of an "unknown" answer sheet from a final exam is provided. Each "unknown" EEG is worth 8 total points (-Fig. 7). Both exams consist of a seizure video, multiple choice questions, and "EEG unknowns." Students are provided with a blank answer grid to fill out for the "EEG unknowns" and a montage sheet containing the 6 montages for reference. In addition, each student's progress is followed and discussed during weekly staff meetings. Neurology residents from UH are also evaluated on "Resident Milestones" as mandated by the Accreditation Council for Graduate Med- ical Education, as requested by the neurology residency program director. At the completion of the course, the participants have achieved a level of competency in the analysis and interpretation of electrography with added knowledge in SS, antiepileptic drugs, and various related topics as they pertain to epileptic disorders. The incoming epilepsy and clinical neurophysiology fellows at UHCMC are then able to immediately utilize the knowledge gained from the 2-month course at the start of their clinical training.

Finally, the course participants are encouraged to submit anonymous feedback regarding the course. This information has been utilized to improve the course. For example, a lecture on neuroimmunology relative to epilepsy was recently added to the course in response to feedback from a participant.

In summary, the success of the course has been validated by former participants, who over time have themselves become educators, given the fact that they have been sending their trainees to the course. 


\begin{tabular}{|c|c|c|c|c|}
\hline \multicolumn{5}{|c|}{ *Week 3 (Dr. Lüders) } \\
\hline Monday & Tuesday & Wednesday & Thursday & Friday \\
\hline $\begin{array}{c}\text { 8:00-9:15 } \\
\text { Frohring Auditorium } \\
\text { School of Medicine } \\
\text { Epilepsy Grand Rounds } \\
\text { Topic: TBA }\end{array}$ & $\begin{array}{c}\text { 8:00 - 9:15 } \\
\text { Hanna House } 537 \\
\text { Fellow EEG Conference } \\
\text { Dr. Hans Lüders }\end{array}$ & $\begin{array}{c}\text { 8:30-9:15 } \\
\text { Bolwell 5198-5199 } \\
\text { Case Study } \\
\text { Dr. Hans Lüders }\end{array}$ & $\begin{array}{c}\text { 8:00-9:15 } \\
\text { Hanna House } 537 \\
\text { Fellow Clinical } \\
\text { Epilepsy Conf } \\
\\
\text { Dr. Hans Lüders }\end{array}$ & $\begin{array}{c}\text { 8:00-9:15 } \\
\text { Kulas Auditorium } \\
\text { Neurology Grand Round } \\
\text { Topic: TBA }\end{array}$ \\
\hline $\begin{array}{c}\text { 9:30-11:00 } \\
\text { Bolwell 5198-5199 } \\
\text { Dr. Hans Lüders } \\
\text { General Epileptology } \\
\text { Principles }\end{array}$ & $\begin{array}{c}\text { 9:30-11:00 } \\
\text { Bolwell 5198-5199 } \\
\text { Dr. Hans Lüders } \\
\text { Classification Paroxysmal } \\
\text { Events } \\
\text { Epileptic Auras }\end{array}$ & $\begin{array}{c}\text { 9:15-11:00 } \\
\text { Bolwell 5198-5199 } \\
\text { Dr. Hans Lüders } \\
\\
\text { Dialeptic Seizures } \\
\text { Automotor Seizures } \\
\text { Simple Motor Seizures }\end{array}$ & $\begin{array}{c}\text { 9:30-11:00 } \\
\text { Bolwell 5198-5199 } \\
\text { Dr. Hans Lüders } \\
\text { Complex Motor Seizures } \\
\text { Special Seizures } \\
\text { Somatotopic Modifiers }\end{array}$ & $\begin{array}{c}\text { 9:30-11:00 } \\
\text { Bolwell 5198-5199 } \\
\text { Dr. Hans Lüders } \\
\text { Lateralizing Signs }\end{array}$ \\
\hline $\begin{array}{l}\text { 11:00-12:00 } \\
\text { EEG Discussion } \\
\text { Dr. Lüders }\end{array}$ & $\begin{array}{c}\text { 11:00-12:00 } \\
\text { EEG Discussion } \\
\text { Dr. Lüders }\end{array}$ & $\begin{array}{l}\text { 11:00-12:00 } \\
\text { EEG Discussion } \\
\text { Dr. Lüders }\end{array}$ & $\begin{array}{l}\text { 11:00-12:00 } \\
\text { EEG Discussion } \\
\text { Dr. Lüders }\end{array}$ & $\begin{array}{l}\text { 11:00-12:00 } \\
\text { EEG Discussion } \\
\text { Dr. Lüders }\end{array}$ \\
\hline $\begin{array}{c}\text { 1:30-2:30 } \\
\text { Bolwell 5198-5199 } \\
\text { EEG Reading } \\
\text { Dr. Lüders }\end{array}$ & $\begin{array}{c}\text { 1:30-2:30 } \\
\text { Bolwell 5198-5199 } \\
\text { EEG Reading } \\
\text { Dr. Lüders }\end{array}$ & $\begin{array}{c}\text { 1:30-2:30 } \\
\text { Bolwell 5198-5199 } \\
\text { EEG Reading } \\
\text { Dr. Lüders }\end{array}$ & $\begin{array}{c}\text { 2:30-3:30 } \\
\text { Hanna House } 537 \\
\text { Epilepsy Case Conference }\end{array}$ & $\begin{array}{c}\text { 1:30-2:30 } \\
\text { Bolwell 5198-5199 } \\
\text { EEG Reading } \\
\text { Dr. Lüders }\end{array}$ \\
\hline
\end{tabular}

Fig. 6 Sample of a weekly schedule.

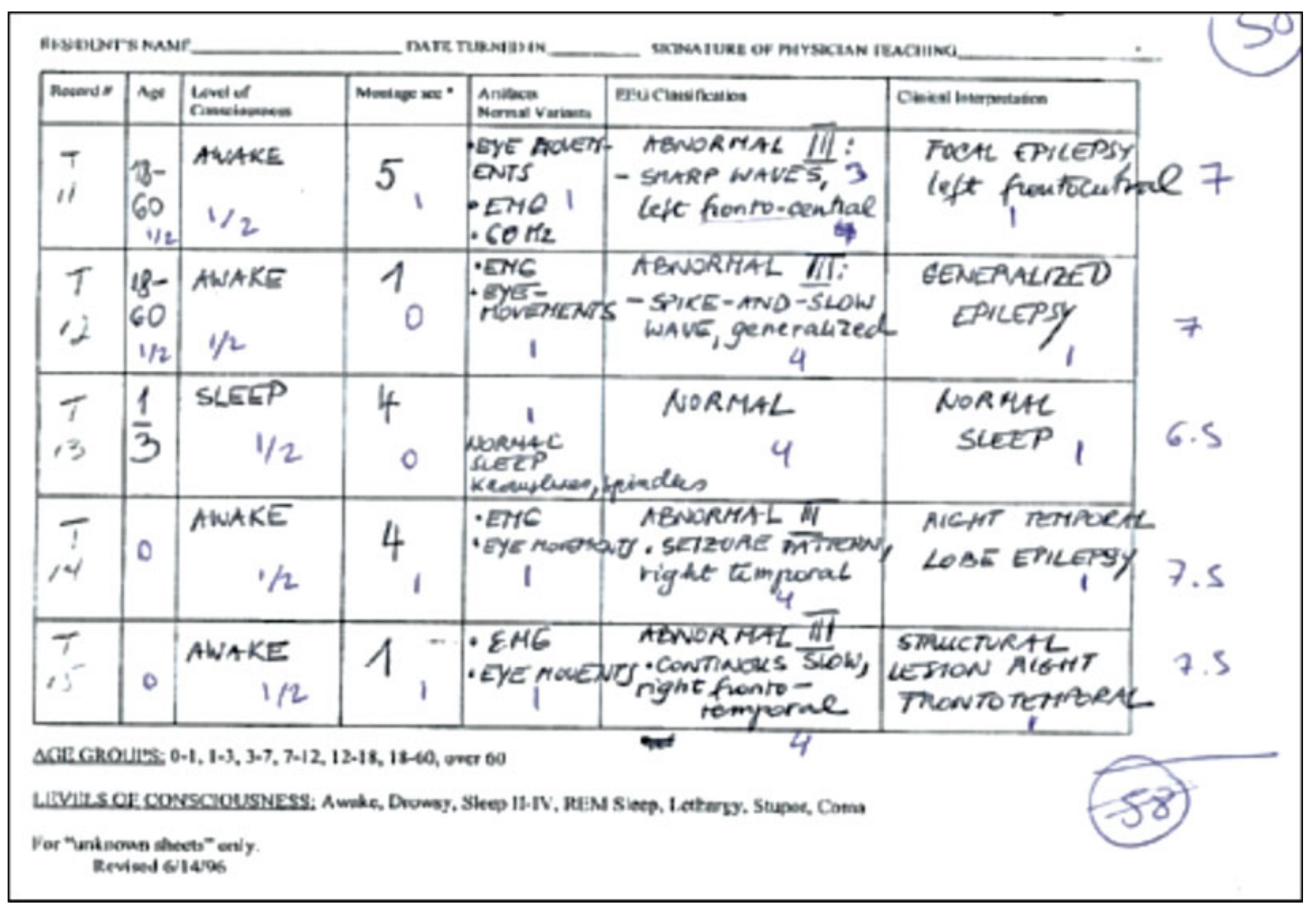

Fig. 7 Sample of a student's "unknown electroencephalography (EEG)" answer sheet from final exam. 
10 Electroencephalography and Epilepsy Course at UH Cleveland Medical Center Park et al.

\section{Conclusion}

Prof. Lüders began the International EEG/Epilepsy course in Cleveland (Ohio, United States) 40 years ago with the aim to impart a foundation of knowledge in EEG and epilepsy through an intensive, structured didactic course which has remained free of charge. The course contents evolved over the years to reflect changes in the field of epilepsy. At the same time, however, the fundamentally important methodological core of EEG analysis has changed only little. In an era of technological advancement with the invention of powerful tools to guide in the localization of the epileptogenic zones, ability to correctly correlate SS and EEG findings remains pivotal. Over the years, many clinicians and scientists from the United States and beyond who have attended the course have then utilized the knowledge gained in these courses to advance the field of EEG and epilepsy at their local hospitals and institutions. The course information is available at https://www.uhdoctor.org/eeg/ epilepsy-course.

\section{Note}

This study was presented at the American Epilepsy Society (AES) 71st Annual Meeting 2017, Washington, District of Columbia.
Conflict of Interest

None declared.

\section{References}

1 Sahoo SS, Zhao M, Luo L, et al. OPIC: Ontology-driven Patient Information Capturing system for epilepsy. AMIA Annu Symp Proc 2012;2012:799-808

2 Lüders HO, Noachtar S. Atlas and Classification of Electroencephalography. Illustrated. Philadelphia: WB Saunders; 2000:204

3 Loddenkemper T, Kellinghaus C, Wyllie E, et al. A proposal for a five-dimensional patient-oriented epilepsy classification. Epileptic Disord 2005;7(04):308-316

4 Lüders H, Vaca GF-B, Akamatsu N, et al. Classification of paroxysmal events and the four-dimensional epilepsy classification system. Epileptic Disord 2019;21(01):1-29

5 Lüders HO, Burgess R, Noachtar S. Expanding the international classification of seizures to provide localization information. Neurology 1993;43(09):1650-1655

6 Lüders H, Acharya J, Baumgartner C, et al. Semiological seizure classification. Epilepsia 1998;39(09):1006-1013

7 Lüders H, Acharya J, Baumgartner C, et al. A new epileptic seizure classification based exclusively on ictal semiology. Acta Neurol Scand 1999;99(03):137-141

8 Lüders HO, Amina S, Baumgartner C, et al. Modern technology calls for a modern approach to classification of epileptic seizures and the epilepsies. Epilepsia 2012;53(03):405-411

9 Rona S, Rosenow F, Arnold S, et al. A semiological classification of status epilepticus. Epileptic Disord 2005;7(01):5-12 